\title{
A reconstrução dos direitos humanos: a contribuição de Hannah Arendt
}

\author{
CELSO LAFER
}

"M

UITAS COISAS sabe a raposa; mas o ouriço uma grande". A partir deste verso do poeta grego Arquíloco, Isaiah Berlin propôs sua conhecida classificação de escritores e pensadores. Os ouriços seriam aqueles que tudo referem a uma visão unitária e coerente, a qual opera como um projeto organizador fundamental de tudo o que pensam. Tendem, portanto, a uma perspectiva centrípeta e monista da realidade. As raposas seriam aqueles que se interessam por coisas várias, perseguem múltiplos fins e objetivos, cuja interconexão, ademais, não é nem óbvia nem explícita. A tendência que aí se manifesta é centrífuga e pluralista.

A classificação ouriço/raposa apresenta, como qualquer dicotomia, o risco da simplificação, mas pode ser um ponto de partida para análises extremamente fecundas. É o caso, se tiver como nota um distinguo, ou seja, uma capacidade heurística de indicar diferenças e dissimilitudes. Esta capacidade, como aponta Hobbes, é um ingrediente do discernimento indispensável para um bom julgamento. A qualidade deste juízo tende a aumentar (diria eu, como raposa) se, adicionalmente, a dicotomia não partir de uma visão taxativa de duas partes incomunicáveis, num aut/aut que absolutiza a diferença, mas for concebida como pólos de um contínuo com função pluralista voltada para iluminar uma realidade ontologicamente complexa. É nesta linha, seguindo a lição metodológica de Norberto Bobbio, que me valerei da dicotomia raposa/ouriço para discutir a contribuição de Hannah Arendt para a temática dos direitos humanos, fruto de uma reflexão sobre o significado do totalitarismo.

Hannah Arendt pensadora é tanto ouriço quanto raposa. No que toca ao tema dos direitos humanos, ela é um ouriço no diagnóstico e na avaliação, ao identificar na ruptura trazida pela experiência totalitária do nazismo e do stalinismo a inauguração do tudo é possivel. O tudo é possível levou pessoas a serem tratadas, de jure e de facto, como supérfluas e descartáveis.

Tal fato contrariou frontalmente os valores consagrados da Justiça e do Direito - valores voltados a evitar a punição desproporcional; a distribuição nãoeqüitativa de bens e situações; o descumprimento das promessas e compromissos (pacta sunt servanda). 
Disso resultou o esfacelamento dos padrões e categorias que, com base na idéia de um Direito Natural, constituíam o conjunto da tradição ocidental a qual havia historicamente feito da pessoa humana um valor-fonte da experiência éticojurídica. Conseqüentemente, disso adveio também o hiato entre o passado e o futuro. Esse hiato gera constantes perplexidades no presente, já que a tradição - inclusive a do pensamento jurídico - não nos oferece critérios para a ação futura, nem conceitos para o entendimento dos acontecimentos passados.

Ela é raposa, por sua vez, na sua percepção da realidade - que vê como ontologicamente complexa e rica nas suas particularidades e contingências - e na sua proposta de reconstrução, após a ruptura já diagnosticada. Tal proposta fundamenta-se em uma retomada crítica do pensamento ocidental, que almeja o exame das condições políticas e jurídicas que permitam assegurar um mundo comum. Um mundo marcado pela pluralidade e pela diversidade e vivificado pela criatividade do novo, o qual, através do exercício da liberdade inerente à visão arendtiana de natalidade, impediria o ressurgimento de um novo estado totalitário de natureza.

No mundo contemporâneo continuam a persistir situações sociais, políticas e econômicas que, mesmo depois do término dos regimes totalitários, contribuem para tornar os homens supérfluos e sem lugar num mundo comum. Entre outras tendências, menciono a ubiqüidade da pobreza e da miséria; a ameaça do holocausto nuclear; a irrupção da violência, os surtos terroristas, a limpeza étnica, os fundamentalismos excludentes e intolerantes.

Cabe, igualmente, salientar que a coincidência entre a explosão demográfica e a descoberta de novas técnicas aponta para a possibilidade terrível de que segmentos inteiros da população possam se tornar descartáveis do ponto de vista da produção. Em síntese, continua relevante e atual a preocupação de Hannah Arendt enquanto ouriço, pois os seres humanos têm múltiplas razões para não se sentir nem à vontade nem em casa no mundo. Daí o interesse de um diálogo com seu pensamento e com as pistas que a sua dimensão de raposa oferecem para uma reflexão sobre as condições de possibilidade de aprimorar a convivência coletiva através da asserção dos direitos humanos.

Foi o que tentei fazer no meu livro A reconstrução dos direitos humanos: um diálogo com o pensamento de Hannah Arendt (São Paulo, Cia. das Letras, 1988), do qual este texto é uma sinopse aggiornata. Devo, no entanto, esclarecer que, sendo fragmentária a reflexão arendtiana sobre os direitos humanos, o diálogo que conduzi e conduzo com o seu pensamento se baseia em uma ampla liberdade. Esta liberdade encontra precedente e pretexto na própria maneira como Hannah Arendt repensou os clássicos e, por exemplo, apropriou-se livremente da Crítica do juizo de Kant, fazendo-a fertilizar uma filosofia política distinta mas não incompatível com uma visão kantiana. Sigo, assim, o selbstdenken que ela tanto apreciava em Lessing e que com ela aprendi quando tive o privilégio de ser seu aluno na Universidade de Cornell nos Estados Unidos. 
Para Hannah Arendt, a ruptura no plano jurídico surge quando a lógica do razoável que permeia a reflexão jurídica não consegue dar conta da nãorazoabilidade que caracteriza uma experiência como a totalitária. Esta não resultou de uma ameaça externa, mas foi gerada no bojo da própria modernidade, como um desdobramento inesperado e não-razoável de seus valores.

O totalitarismo, em suma, é uma proposta inédita de organização da sociedade que escapa ao senso comum (sensus communis) do estar entre os homens (inter-homines esse), posto que, desconcertante para qualquer medida ou critério razoável de Justiça tradicionalmente relacionado à punição proporcional ao ato punível; a distribuição eqüitativa de bens e situações e a boa-fé inerente ao pacta sunt servanda. É, com efeito, uma nova forma de governo que, ao almejar a dominação total através do uso da ideologia e do emprego do terror para promover a ubiqüidade do medo, fez do campo de concentração o seu paradigma organizacional. Fundamenta-se, assim, no pressuposto de que os seres humanos, independentemente do que fazem ou aspiram, podem, a qualquer momento, ser qualificados como inimigos objetivos e encarados como supérfluos para a sociedade. Tal convicção explicitamente assumida pelo totalitarismo, de que os seres humanos são supérfluos e descartáveis, representa uma contestação frontal à idéia do valor da pessoa humana enquanto valor-fonte da legitimidade da ordem jurídica, como formulada pela tradição, senão como verdade pelo menos como conjectura plausível da organização da vida em sociedade.

Daí a necessidade de precisar como ocorreu especificamente essa ruptura no plano jurídico e quais são algumas das respostas possíveis a tal situação.

O valor da pessoa humana como valor-fonte da ordem da vida em sociedade encontra a sua expressão jurídica nos direitos humanos. Estes foram, a partir do século XVIII, positivados em declarações constitucionais. Tais positivações buscavam, para usar as categorias arendtianas, a durabilidade do work do homo-faber, através de normas da hierarquia constitucional. Tinham como objetivo tornar aceitável, ex parte populi o estar entre os homens (o inter homines esse) em sociedades que se caracterizariam pela variabilidade do Direito Positivo - a sua dimensão de labor - requerida pelas necessidades da gestão do mundo moderno, tal como percebidas pelos governantes.

O elenco dos direitos humanos contemplados pelo Direito Positivo foi se alterando do século XVIII até os nossos dias. Assim caminhou-se historicamente dos direitos humanos de primeira geração - os direitos civis e políticos de garantia, de cunho individualista voltados para tutelar a diferença entre Estado e Sociedade e impedir a dissolução do indivíduo num todo coletivo - para os direitos de segunda geração - os direitos econômicos, sociais e culturais concebidos como créditos dos indivíduos com relação à sociedade, a serem saldados pelo Estado em nome da comunidade nacional. $\mathrm{O}$ processo de asserção histórica das duas gerações de direitos humanos, que são direitos de titularidade individual, foi inspirado pelos legados cosmopolita e universalista do liberalismo e do socialismo. 
Tal processo ocorreu, no entanto, na moldura ex parte populi da soberania nacional, consoante o modelo da Revolução Francesa, ou seja, foi conjugado no âmbito de um espaço que consagrava um direito popular de titularidade coletiva: o do princípio das nacionalidades. Este princípio foi substituindo o princípio dinástico dos regimes monárquicos enquanto critério do crescente reconhecimento internacional da legitimidade da soberania.

A convergência entre os direitos humanos e os direitos dos povos baseavase no pressuposto implícito de que o padrão de normalidade era a distribuição, em escala mundial, dos seres humanos entre os Estados de que eram nacionais - um padrão colocado em questão pelas realidades históricas do primeiro pós-guerra. Foi o surgimento em larga escala dos refugiados e apátridas - os expulsos da trindade Povo-Estado-Território - que assinalou, com a emergência do totalitarismo, o ponto de ruptura cujo cerne foi a dissociação entre os direitos humanos e os direitos dos povos.

De fato, à medida em que os refugiados e apátridas se viram destituídos, com a perda da cidadania, dos benefícios do princípio da legalidade, não puderam se valer dos direitos humanos, e não encontrando lugar - qualquer lugar - num mundo como o do século XX, inteiramente organizado e ocupado politicamente, tornaram-se efetivamente desnecessários, porque indesejáveis erga omnes, e acabaram encontrando o seu destino e lugar natural nos campos de concentração.

A experiência histórica dos displaced people levou Hannah Arendt a concluir que a cidadania é o direito a ter direitos, pois a igualdade em dignidade e direito dos seres humanos não é um dado. É um construído da convivência coletiva, que requer o acesso a um espaço público comum. Em resumo, é esse acesso ao espaço público - o direito de pertencer a uma comunidade política - que permite a construção de um mundo comum através do processo de asserção dos direitos humanos.

A construção de um mundo comum, baseado no direito de todo ser humano à hospitalidade universal (Kant) e contestado na prática pelos refugiados, pelos apátridas, pelos deslocados, pelos campos de concentração, só começaria a ser tornada viável - como aponta inicialmente Hannah Arendt em The rights of men. What are they? (1949) e desenvolve depois em The origins of totalitarianism - se o direito a ter direitos tivesse uma tutela internacional, homologadora do ponto de vista da humanidade. Nas palavras de Hannah Arendt, no fecho deste artigo de 1949: "This human right, like all other rights can exist only through mutual agreement and guarantee. Transcending the rights of the citizen - being the right of men to citizenship - this right is the only one that can and can only be guaranted by the comunity of nations". Em síntese, para usar uma linguagem contemporânea, à medida em que o direito a ter direitos se convertesse num tema global, de governança da ordem mundial, a transcender as soberanias, ex vi da inserção operativa de uma razão abrangente da humanidade.

As conseqüências e a atualidade da conclusão arendtiana foram reconhecidas pelo Direito Internacional Público contemporâneo, o qual passou a considerar a nacionalidade como um direito humano fundamental, além de buscar substi- 
tuir as insuficiências do mecanismo de proteção diplomática pelas garantias coletivas, confiadas a todos os Estados-partes nas Convenções Internacionais dos Direitos Humanos.

A situação de fato que criou as condições para o genocídio foi justamente o problema dos seres humanos supérfluos e como tais encarados, posto pela experiência totalitária e juridicamente ensejado pela privação da cidadania. Aqueles que se viram reduzidos a "mera existência em todos os assuntos de interesse público" foram arrebanhados, por falta de um lugar no mundo, nos campos de concentração.

O genocídio não é um crime contra um grupo nacional, étnico, racial ou religioso. É um crime que ocorre, lógica e praticamente, acima das nações e dos Estados - das comunidades políticas. É um tema global, pois diz respeito ao mundo como um todo. Trata-se, portanto, de um crime contra a humanidade que assinala, pelo seu ineditismo, a especificidade da ruptura totalitária. A ruptura totalitária levou, assim, no pós-Segunda Guerra Mundial, à afirmação de um Direito Internacional Penal. Este procura tutelar interesses e valores de escopo universal, cuja salvaguarda é fundamental para a sobrevivência não apenas de comunidades nacionais, de grupos étnicos, raciais ou religiosos minoritários, mas da própria comunidade internacional. Entre tais valores e interesses está a repressão ao genocídio.

Este é um ingrediente básico das conclusões de Hannah Arendt no seu livro sobre o processo Eichmann. O crime de genocídio, administrado por Eichmann e perpetrado no corpo do povo judeu, é um crime contra a humanidade porque é uma recusa frontal da diversidade e da pluralidade - características da condição humana na proposta arendtiana de um mundo plural. A fundamentação da repressão ao genocídio na visão arendtiana baseia-se, assim, na sua análise da condição humana in The human condition e nos princípios kantianos, por ela esposados nas suas Lectures on Kant's political philosophy, da hospitalidade universal e da confiança recíproca, articulados no Projeto de paz perpétua. A hospitalidade universal vem a ser um princípio de jus cogens de ordem internacional, pois o fato de o genocídio ter ocorrido é um precedente que ameaça a ordem pública internacional. Nenhum povo da terra pode se sentir razoavelmente seguro de sua existência e sobrevivência e, portanto, à vontade e em casa no mundo, na medida que se admite o genocídio como uma possibilidade futura, pois esta possibilidade compromete o também kantiano princípio da confiança recíproca.

Cabe aqui observar que a análise de Hannah Arendt - voltada para a natureza e a tipificação do crime de genocídio, e não movida pelo sofrimento das vítimas - foi criticada por falta de compaixão e tida como carência de amor ao povo judeu. Na verdade está de acordo com a tradição judaica, bíblica e talmúdica, a qual afirma concomitantemente a unidade do gênero humano e o pluralismo das nações. Dessa maneira, é uma tradição que oferece igualmente elementos para a tipificação do crime de genocídio, compatíveis com os propostos por Hannah Arendt. 
O totalitarismo, na exata medida que representou uma proposta de organização do Estado e da Sociedade, que escapa ao sensus communis de qualquer critério razoável de Justiça, tornou a propor em novos termos o tema clássico da resistência à opressão e, por via de conseqüência, o da obrigação política. É a partir desta mise-au-point que cumpre analisar inicialmente a contribuição de Hannah Arendt ao alcance do direito de associação. O direito de associação é um ingrediente indispensável à análise do poder como agir em conjunto e, conseqüentemente, ao por que poder e autoridade, que são conceitos distintos, não se confundem com violência. Daí flui, na minha leitura, a relação entre Direito e Poder na perspectiva de Hannah Arendt e o significado que se pode dar à desobediência civil com base no seu pensamento.

Como observou Habermas, Hannah Arendt, na sua reflexão, não se preocupou com a aquisição e a manutenção do poder, nem com o seu uso pelos governantes, mas sim com o que a isto antecede: a sua geração pelos governados. O potestas in populo ciceroniano, para ela, quer dizer o poder entendido como a aptidão humana para agir em conjunto. Daí a importância decisiva do direito de associação para uma comunidade política, pois é a associação que gera o poder de que se valem os governantes. Por isso, em última instância, a questão da obediência à lei não se resolve pela força, como afirma a tradição, mas sim pela opinião e pelo número daqueles que compartilham o curso comum de ação expresso no comando legal. Em síntese, a pergunta essencial não é por que se obedece a lei, mas por que se apoia a lei, obedecendo-a.

O poder não necessita de justificação, mas requer legitimidade que Hannah Arendt vincula à autoridade, categoria que ela examina em Between past and future, mostrando as suas origens romanas. Deriva do início da ação conjunta, do ato de fundação da comunidade política ( $a b$ urbe condita).

O tema da gênese do nós de uma comunidade política, que Hannah Arendt também enfatizou em Willing (o segundo volume de The life of the mind) - chamando atenção para a discussão que Kant empreende na Crítica da razão pura a respeito do início espontâneo de uma nova série de coisas ou situações - é relevante para o entendimento, no mundo moderno, da Revolução como um evento sem precedentes.

De fato, foi só a partir da Revolução Francesa que uma renovatio ex parte populi ab imis fundamentis, de natureza interna, passou a ser encarada como eventomatriz, transformador e instaurador da autoridade, deixando de ser vista como revolta e rebeldia desagregadoras da ordem.

É a importância desse evento-matriz que carrega no seu bojo a esperança do inaugural contida na fundação do nós de uma nova comunidade política (mas também os riscos dos seus descaminhos, examinados por Hannah Arendt em $\mathrm{On}$ revolution), o que levou a teoria política a atribuir legitimidade à noção de soberania popular e ao princípio das nacionalidades. 
O Direito Internacional Público Contemporâneo, ao tutelar o princípio de autodeterminação dos povos, como critério de independência e autonomia dos Estados, chancela a importância atribuída por Hannah Arendt à fundação do nós de uma comunidade política e reconhece a esperança que pode trazer a liberação de uma antiga ordem colonial ou baseada em impérios dinásticos por meio da liberdade do agir conjunto.

Poder e Autoridade são fenômenos plurais de natureza coletiva, distintos, pela sua natureza, da força, do vigor e da violência, que se colocam no singular. Daí a crítica de Hannah Arendt à criatividade da violência no campo da política, em conhecido ensaio, recolhido em Crisis of the republic.

A violência tem caráter instrumental e, no mundo contemporâneo, o seu alcance viu-se multiplicado pela técnica. De acordo com Hannah Arendt, a violência ex parte populi, no campo da política, é uma resposta à hipocrisia dos governantes que converte governados engagés em enragés. Tal resposta pode representar uma resistência à opressão. Não gera, no entanto, poder. Este sempre resulta do agir conjunto, que se baseia no direito de associação e requer a comunicação entre as pessoas no espaço público e, portanto, o direito à informação como adiante se verá. Por isso, poder não se confunde com força e violência e estas, quando deixam de ser reação e se convertem em estratégia, são destrutivas da faculdade do agir e, conseqüentemente, impeditivas do poder que gera e vivifica uma comunidade política.

Depois dessa crítica aos meios violentos da resistência à opressão, meios que apenas destroem a autoridade e o poder mas não os criam ou os substituem, cabe sublinhar, inspirado na reflexão de Hannah Arendt em The human condition, a complementaridade entre Direito e Política para o entendimento da obrigação política. O Direito é constitutivo e regulador da ação política, requer consenso e se fundamenta na promessa, categoria que Hannah Arendt reelabora na sua análise de ação juntamente com a do perdão.

A promessa estabelece um limite estabilizador necessário à imprevisibilidade e à criatividade da ação. Daí a importância, na interação humana, do pacta sunt servanda ciceroniano, no qual se fundamenta o Direito. Uma constituição - como mostra Hannah Arendt na análise da experiência norte-americana que, em $O n$ revolution, ela discute como metáfora exemplar do poder constituinte originário tem duas dimensões que esclarecem a relação entre Direito e Política de maneira mais concreta. São elas a da construção pelo homo faber do espaço público, e a da obtenção do acordo para o agir conjunto, por meio da promessa. A Constituição é, portanto, um construído convencional, no qual a contingência do consenso, cuja autoridade deriva do ato de fundação, é uma virtude, pois a verdade da lei repousa na convenção criadora de uma comunidade política, que enseja a gramática da ação e a sintaxe do poder.

$\mathrm{E}$, porque as comunidades políticas não são produto do pensamento mas resultado da ação - da vita activa -, as constituições não têm existência independente. Não são apenas uma obra de técnica do homo faber - do grande legislador. 
Estão sujeitas a outros sucessivos atos e dependem deles para subsistir. É por essa razão que é preciso preservar as condições para a gramática da ação e para a sintaxe do poder, a fim de que haja obediência à lei.

É possível resgatar tal dimensão da obrigação política no mundo contemporâneo? Um mundo avassalado pela destrutividade em larga escala da violência; no qual a Lei se esvai no metabolismo do labor da administração da sociedade e onde todos experimentam a crescente multiplicação das possibilidades da opressão que corrói a autoridade do Direito?

Uma resposta esperançosa a esses dilemas, que dificultam a afirmação de uma obrigação política autêntica, permeia a reflexão arendtiana. Ela passa pela criatividade da política, pelo potencial do novo - de um initium agostiniano - que o agir conjunto, baseado na associação entre os homens no espaço público, oferece ao desafio da ruptura. É o que Hannah Arendt explora, com a sua capacidade de pensar teoricamente a partir de situações concretas, no ensaio sobre a experiência norte-americana de desobediência civil.

Nesse ensaio, ela mostra como a desobediência civil é uma forma extrema de dissentimento que, ao se exprimir por meio da associação, fala a linguagem da persuasão, resgata a faculdade de agir, gera poder pela ação conjunta de muitos e se coloca na esfera do interesse público.

Hannah Arendt entende que, em situações-limite - uma categoria de existencialismo, de inspiração jasperiana, importante na sua reflexão -, a desobediência civil é legítima e pode ser bem sucedida na resistência à opressão. Foi o caso por ela comentado em Eichmann in Jerusalem: a report on the banality of evil, da resistência dos dinamarqueses, através da desobediência civil, à política anti-semita do invasor nazista. Foi o que conduziu a luta de Ghandi. Foi também o caso da luta contra a segregação racial e da resistência à guerra do Vietnã, a partir das quais ela refletiu sobre a desobediência civil no ensaio mencionado, que integra Crisis of the republic. De fato, nesses casos, a desobediência civil, sendo a expressão de um empenho político coletivo na resistência à opressão, não se constitui como rejeição da obrigação política, mas a sua reafirmação.

A análise que Hannah Arendt faz da desobediência civil é criativa por se afastar da lógica do razoável, que não dá conta das realidades contemporâneas. Devo ressalvar, também, que esta análise carece de standards que permitam identificar situações-limite. Tal carência coloca problemas sérios, pois, sem estes standards, a prática generalizada da desobediência civil pode levar à anarquia e à ingovernabilidade. De fato, no contexto de uma legitimidade centrífuga e tópica que caracteriza o mundo contemporâneo, em parte resultado de uma reação à ruptura totalitária, o particularismo compromete a idéia de unidade que preside o conceito de comunidade política na elaboração teórica, o qual vai da polis grega ao Estado Moderno e é fundamental para a governabilidade. Este ponto é importante, pois a defesa da anarquia não é a posição arendtiana, que não pretende o desaparecimento do poder e da autoridade, mas a sua recuperação. 
Aludo brevemente a outro tópico da reconstrução dos direitos humanos que se pode extrair do pensamento de Hannah Arendt e tem também a sua origem na reflexão sobre a experiência totalitária. Refiro-me ao que ela aponta nas conclusões do The origin of totalitarianism sobre o "isolamento" que leva à impotência, frustrando a capacidade humana para ação e o poder na esfera pública, e sobre a "desolação" (loneliness), que destrói a vida privada, exacerba o desenraizamento, impede o pensamento e reduz a condição humana exclusivamente ao metabolismo de animal laborans. Impedir o isolamento e a desolação permite fundamentar o direito à informação e o direito à intimidade, com base num distinguo entre o público e o privado.

Para Hannah Arendt - como ela explicita em The human condition - o público é simultaneamente o comum e o visível. Daí a importância da transparência do público por meio do direito ex parte populi à informação, ligado à democracia, como forma de vida e de governo, que requer uma cidadania apta a avaliar o que se passa na res publica para dela poder participar. Sem o direito à informação, não se garante a sobrevivência da verdade factual - a verdade da política -, na qual se baseia a interação e o juízo político, abrindo-se uma margem incontrolada para a mentira e os segredos conservados pelos governantes nas arcana imperii. Tanto as mentiras quanto os segredos corrompem o espaço público. A transparência do público através de uma informação honesta e precisa é, portanto, condição para o juízo e a ação numa autêntica comunidade política.

Para Hannah Arendt, coerente com o seu entendimento do público como o comum e o visível, o privado, na dimensão da intimidade, é aquilo que é exclusivo do ser humano na sua individualidade e, não sendo de interesse público, não deve ser divulgado.

A intimidade, como um direito autônomo da personalidade, foi articulada conceitualmente por Rousseau como resposta do indivíduo ao conformismo nivelador da sociedade, aquilo que Hannah Arendt qualifica como "o surgir do social". Na fundamentação de sua tutela, entendo que Hannah Arendt oferece como critério para limitar o direito à informação o princípio de exclusividade. Esse critério, articulado nos seus textos Reflections on Little Rock e Public rights and private interests, é compatível com os preceitos kantianos de publicidade, por ela esposados, à medida em que a intimidade enquanto the right to be let alone não envolve direitos de terceiros.

A reconstrução do tema dos direitos humanos elaborada com base em desenvolvimento ou sugestões contidas na obra de Hannah Arendt não leva a um sistema. Permite, no entanto, identificar problemas que são importantes e se tornaram relevantes em virtude da ruptura totalitária e dos seus desdobramentos. A identificação de tais problemas resulta de um juízo, uma faculdade da mente com que Hannah Arendt se preocupou - é, na verdade, um tema recorrente de sua reflexão - mas sobre a qual não chegou a escrever, e que seria o fecho de The life of the mind, seu último livro, publicado postumamente. 
O juízo, entendido kantianamente como a faculdade de pensar o particular contido no geral, é um dos temas fundamentais do Direito, por ser uma das características da experiência jurídica moderna o processo através do qual o caso concreto é qualificado e subsumido pela norma geral. A lógica do razoável no pensamento jurídico explorou amplamente, em matéria de hermenêutica jurídica, as dificuldades da subsunção. Entretanto, sempre partiu do pressuposto de existir um geral, ao qual se possa razoavelmente recorrer por meio de interpretação.

Precisamente porque articulou, como um ouriço, a ruptura que dissolveu o geral, Hannah Arendt se deu conta da inexistência de um sistema de universais para aquilo que desborda da lógica do razoável. Por isso, toda a sua reflexão tem como horizonte o problema de como julgar um particular, para o qual não existe previamente o dado de um universal. Foi por essa razão que, diante das dificuldades do juízo determinante em situações-limite provenientes da impossibilidade de se aplicar uma regra universal de entendimento a um caso particular, ela explorou o campo dos juízos reflexivos e raciocinantes. Estes entreabrem a faculdade de pensar o particular, através de sua validade exemplar, que pode ser realçada e comunicada.

O juízo reflexivo e raciocinante - que Kant examina na Crítica do juizo - na análise da estética foi o ponto de partida heurístico de Hannah Arendt para unir a teoria à prática na sua proposta de reconstrução, como se vislumbra nas suas Lectures on Kant's political philosophy, também publicadas postumamente sob os cuidados de Ronald Beiner.

Tal proposta harmoniza-se com a sua visão de raposa perante um mundo percebido centrifugamente, pois a importância dos juízos reflexivos e raciocinantes deriva da relação problemática entre o universal e o particular que a ruptura tornou evidente. Em síntese: precisamente porque o juízo, no mundo contemporâneo, não pode ser reduzido a uma fórmula inequívoca de subsunção é que se pode falar no seu peso e na sua responsabilidade.

Hannah Arendt assumiu, com a sua obra, o ônus e a responsabilidade de juízos reflexivos e raciocinantes, que são esforços de mediação entre o particular e um universal fugidio. Ela nos convida a fazer a mesma coisa. Não é fácil aceitar tal convite, inclusive por força das limitações teóricas e práticas ao que se pode fazer com as indicações por ela deixadas a propósito do juízo. Estas indicações, no entanto, são suficientes para fundamentar por que uma reconstrução pós-totalitarismo do tema dos direitos humanos inspirada em Hannah Arendt só poderia ser tópica - e não sistemática -, mas que existe indiscutível validade nos problemas investigados com base em sua reflexão.

Com efeito, e resumindo para a seguir concluir, quais são os temas de direitos humanos discutidos neste texto, voltados para impedir a reemergência de um novo estado totalitário de natureza, e heuristicamente inspirados por um diálogo livre com o pensamento de Hannah Arendt? São eles:

- a cidadania concebida com o "direito a ter direitos", pois sem ela não se trabalha a igualdade que requer o acesso ao espaço público, pois os direi- 
tos - todos os direitos - não são dados (physei) mas construídos (nomoi) no âmbito de uma comunidade política;

- a repressão ao genocídio concebido como um crime contra a humanidade e fundamentado na tutela da condição humana da pluralidade e da diversidade que o genocídio visa destruir;

- o estudo da obrigação política em conexão: com o direito de associação como a base do agir conjunto e condição de possibilidade da geração de poder; com a dimensão de autoridade e legitimidade da fundação do nós de uma comunidade política e a sua relação com o direito à autodeterminação dos povos; com o poder da promessa e conseqüentemente com o pacta sunt servanda enquanto base da obediência ao Direito; com a resistência à opressão, através da desobediência civil, que em situações-limite pode resgatar a obrigação política da destrutividade da violência;

- o direito à informação, como condição essencial para a manutenção de um espaço público democrático, e o direito à intimidade, indispensável para a preservação do calor da vida humana na esfera privada.

Todos estes temas são, penso eu, uma eloqüente e pertinente indicação da capacidade arendtiana de indicar caminhos teóricos a partir de problemas concretos. Daí os fermenta cognitionis dos tópicos abordados, derivados da experiência de ruptura, que revelam, pela sua validade exemplar, uma generalidade que de outra forma não poderia ser percebida.

Celso Lafer, professor titular de Filosofia e Teoria Geral do Direito da Faculdade de Direito da USP, é chefe da missão do Brasil junto à ONU em Genebra e ex-ministro das Relações Exteriores do Brasil. 